\title{
Efficacy of preemptive Gabapentin for Lower Extremity Orthopedic surgery under Subarachnoid block
}

\author{
Pawan Kumar Hamal, ${ }^{1}$ Amir Babu Shrestha, ${ }^{2}$ Ravi Ram Shrestha ${ }^{1}$ \\ 'National Academy of Medical Sciences, Kathmandu, Nepal, ${ }^{2}$ Paropakar Maternity and Women's Hospital, Thapathali, \\ Kathmandu, Nepal.
}

Introduction: Gabapentin is one of the adjuncts when given before surgery as a multi modal analgesia regimen has shown to decrease pain scores and opioid consumption in the first 24 hour after surgery. The aim of the study is to assess total opioid consumption in first 24 hour postoperatively after giving $600 \mathrm{mg}$ of preemptive oral Gabapentin in lower extremity orthopedic surgery done under subarachnoid block.
\end{abstract}

Methods: A randomized single blinded study was conducted for duration of 6 months after approval from institutional review board. A total of 52 American Society of Anesthesiology physical status grade I and II cases were included in the study of which 26 patients received oral Gabapentin two hours prior to surgery and 26 patients in the control group. They were evaluated postoperatively for total opioid consumption in first 24 hours, Visual Analogue Score after 2, 4, 6 and 24 hours at rest.

Results: Total opioid consumption in first 24 hours was $74.13 \pm 27.78 \mathrm{mg}$ in Gabapentin group versus $123.53 \pm 64.48 \mathrm{mg}$ in Control $(\mathrm{p}=0.001)$. VAS score was $1.23 \pm 1.47$ in Gabapentin group versus 2.12 \pm 1.58 in Control group ( $\mathrm{p}=0.04$ ) at 2 hours and $2.19 \pm 0.40$ in Gabapentin group versus $2.77 \pm 1.17$ in control group $(p=0.02)$ at 24 hours postoperatively at rest which were found to be statistically significant. Incidence of sedation was minimal and comparable in both groups.

Conclusions: Oral Gabapentin 600mg given two hours before surgery reduces total opioid consumption in first 24 hours after surgery and also reduces Visual Analogue score for pain postoperatively at rest in 2 and 24 hours with minimum sedation.

Keywords: analgesia; gabapentin; opioid; preemptive; sedation; visual analogue score.

\section{INTRODUCTION}

Pre-emptive analgesia is a technique of pain control where treatment is initiated before intervention and operational during the surgical procedure in order to reduce the physiological consequences of nociceptive transmission provoked by the procedure. ${ }^{1}$ Gabapentin was introduced in 1993 as an adjuvant anticonvulsant drug for the treatment of refractory partial seizures. Subsequently, it was shown to be effective in treating a variety of chronic pain conditions. ${ }^{2}$ The safety and tolerability of Gabapentin among patients undergoing seizure treatment reported adverse effects such as somnolence, dizziness, asthenia, headache, nausea. ${ }^{3}$ Although the exact mode of action is not known, the alpha- 2 delta subunit of the voltage dependent calcium

Correspondence: Dr. Pawan Kumar Hamal, Consultant Anesthesiologist, National Academy of Medical Sciences, National Trauma Center, Kathmandu, Nepal. Email: pawanhamal@yahoo.com, Phone: +977-9841262246. 
channel is a binding site for Gabapentin at postsynaptic dorsal horn, which produces the antihyperalgesic effects by inhibiting neuronal calcium influx. ${ }^{4}$ Owing to this protective effect on the nociceptive pathways, preemptive analgesia has the potential to be more effective and hence reduce postoperative pain and development of chronic pain. The purpose of the study is to evaluate the postoperative analgesic efficacy of preemptive oral Gabapentin prescribed two hours prior to lower extremity orthopedic surgery done under subarachnoid block.

\section{METHODS}

This is randomized, single blinded, study done in Department of Anesthesiology and Intensive Care, Bir Hospital, Kathmandu, Nepal for period of six months. Patients recruited were randomized into two groups by sealed envelope method. Group $G(n=26)$ received 2 capsules of Gabapentin 300 mg (GABANTIN 300 mg Capsules, Sun Pharmaceuticals) per orally 2 hours before surgery with sips of clear water. Group C (n $=26$ ) is a control group which didn't receive anything. The total sample size of 52 was calculated with 26 each in each arm with reference to study by Montazeri et al $^{13}$ taking total opioid consumption (morphine) in 24 hours after surgery as primary outcome variable with effect size of $2.51 \mathrm{mg}$, pooled Standard Deviation of 2.76, Z-alpha at $95 \%$ confidence interval and Z-beta at $90 \%$. There were no dropouts in both the groups.

Elective lower extremity orthopedic surgeries belonging to American Society of Anesthesiology (ASA) Physical Status Grade I and II, age ranging from 18-60 years with expected surgical duration of 1-3 hours were included in the study. Those who refused and who have contraindications to the use of study drugs and subarachnoid block, patients with renal insufficiency, drug or alcohol abuse, chronic pain syndromes, significant cognitive or psychiatric disorder, pregnant women and intraoperative analgesic use for any conditions were excluded from the study.

\section{Intervention Details}

After ethical approval from Institutional Review Board, patients on the elective operation were assessed one day prior to planned operation with detailed history, physical examination, and necessary laboratory investigations. Written informed consent was taken after appropriate counseling. VAS (Visual Analogue Scale) for pain was discussed with the patient prior to surgery with 0 as no pain and $10 \mathrm{~cm}$ as maximum pain. Patients were kept nil per oral for at least 6 hour from midnight and no premedication was given. Preloading was done with $10 \mathrm{ml} / \mathrm{kg}$ Normal Saline. Subarachnoid block was done in sitting position, midline approach with 25 G Quincke's needle and $0.5 \%$ heavy $3 \mathrm{ml}$ heavy Bupivaicaine. Patients were assessed for sensory level using pinprick method and motor block using Bromage scoring. Failed subarachnoid block was defined as unable to produce adequate sensory block (T8-T10 sensory level) and motor block [Modified Bromage score of at least 2] despite successful lumbar puncture. Pain Scores was assessed on arrival to Post Anesthesia Care Unit at 0 hour and then at 2, 4, 6 and 24 hours at rest after surgery. Injection Pethidine $0.5 \mathrm{mg} / \mathrm{kg}$ plus Promethazine $0.25 \mathrm{mg} / \mathrm{kg}$ was given intramuscularly as rescue analgesic on demand if the VAS score is four or more. Level of sedation was also recorded according to Ramsay Sedation Scale. ${ }^{5}$ Patients with sedation score of four or more was considered sedated.

Data entry and analysis was done in SPSS. Chi-square test was used for Gender and ASA physical status grading. Unpaired t-test was used for total opioid consumptions in 24 hours and time for first rescue analgesia. Mann Whitney test was done for VAS score.

\section{RESULTS}

\begin{tabular}{|c|c|c|c|}
\hline & \multicolumn{2}{|c|}{ Groups } & \multirow[t]{2}{*}{$p$-value } \\
\hline & Control & Gabapentin & \\
\hline Age (years) & $\begin{array}{c}39.12 \pm \\
13.24\end{array}$ & $\begin{array}{c}34.77 \pm \\
8.87\end{array}$ & 0.171 \\
\hline Weight $(\mathrm{kg})$ & $\begin{array}{c}55.23 \pm \\
8.58\end{array}$ & $\begin{array}{c}53.19 \pm \\
9.00\end{array}$ & 0.407 \\
\hline $\begin{array}{l}\text { Duration } \\
\text { of Surgery } \\
\text { (hours) }\end{array}$ & $\begin{array}{c}2.041 \pm \\
0.68\end{array}$ & $\begin{array}{c}1.72 \pm \\
0.55\end{array}$ & 0.07 \\
\hline $\begin{array}{l}\text { Gender } \\
\text { (Male/ } \\
\text { Female) }\end{array}$ & $19 / 7$ & $16 / 10$ & 0.555 \\
\hline ASA $(1 / 2)$ & $24 / 2$ & $23 / 3$ & 0.637 \\
\hline
\end{tabular}

The demographic characteristics in terms of age, weight, duration of surgery, gender and ASA status was not statistically significant and hence comparable in both the groups (Table 1).

Table 2. Total opioid consumption in first 24 hours (Mean \pm Standard Deviation).

\begin{tabular}{|lccc|}
\hline & Group & & p-value \\
& Control & Gabapentin & \\
Total opioid & 123.53 & $74.13 \pm$ & $\mathbf{0 . 0 0 1}$ \\
consumption in & \pm 64.48 & 27.78 & \\
24 hours (mg) & & & \\
\hline
\end{tabular}

The total opioid consumption 24 hours postoperatively 
was reduced significantly with the Gabapentin group (Table 2).

\begin{tabular}{|c|c|c|c|}
\hline \multirow{6}{*}{$\begin{array}{l}\text { VAS at } 2 \\
\text { hours } \\
\text { VAS at } 4 \\
\text { hours } \\
\text { VAS at } 6 \\
\text { hours } \\
\text { VAS at } 24 \\
\text { hours }\end{array}$} & \multirow{2}{*}{\multicolumn{2}{|c|}{$\begin{array}{l}\text { Table 3. Visual analogue Score (VAS) at res } \\
\text { rious duration. } \\
\text { Group (Mean } \pm \text { Standard } \\
\text { Deviation) }\end{array}$}} & \multirow[t]{2}{*}{$\begin{array}{c}\text { p- } \\
\text { value* }\end{array}$} \\
\hline & & & \\
\hline & $2.12 \pm 1.58$ & $1.23 \pm 1.47$ & 0.04 \\
\hline & $2.08 \pm 2.54$ & $2.04 \pm 1.39$ & 0.94 \\
\hline & $2.77 \pm 2.21$ & $2.77 \pm 1.17$ & 0.56 \\
\hline & $2.77 \pm 1.17$ & $2.19 \pm 0.40$ & 0.02 \\
\hline
\end{tabular}

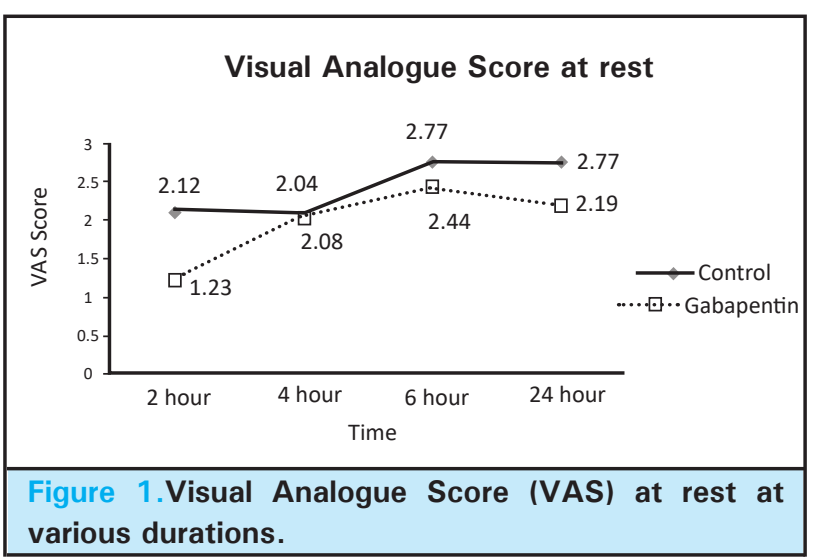

VAS score was decreased at 2, 4, 6 and 24 hours postoperatively at rest. The values were only significant at 2 and 24 hours (Table 3). Sedation score are comparable with both the groups. The incidences of sedation among both the group was found to be 2 (7.6\%).

\section{DISCUSSIONS}

The versatility of Gabapentin in treating a wide array of pain conditions and its favorable side effect profile compared with other drugs or interventions generated interest in its use as a preoperative analgesic. ${ }^{6}$

Our study showed significant reduction in pethidine consumption by $39.99 \%$ in first 24 hours after surgery. A study done in minilaparoscopic cholecystectomy also showed $33 \%$ reduction in opioid consumption with similar dose. ${ }^{7}$ At dose of $600 \mathrm{mg}$ various studies showed reduction in opioid consumption with different surgeries.8,9 Opioid consumption decreased significantly with use of preemptive 600 mg Gabapentin given two hour prior to surgery for laparoscopic cholecystectomy. 7,10 These results are consistent even with use of different opioid with on demand analgesia or use of patient controlled analgesia by various reviews. ${ }^{2,11,12} \mathrm{~A}$ similar study done in cases of lower extremity surgery under general anesthesia had shown significant reduction in 24 hour opioid consumption with use of $300 \mathrm{mg}$ Gabapentin with Tramadol in patient controlled analgesia. ${ }^{13}$ However surgeries undergoing arthroscopic repair under subarachnoid block at 300 $\mathrm{mg}$ does not show reduction in opioid consumption. ${ }^{14}$ The variability in doses of oral Gabapentin required for reducing opioid consumption seems to depend upon type of surgery, invasiveness of the surgery, technique of postoperative analgesia used and also the timing of the preemptive analgesia. The best possible explanation of opioid sparing effects of Gabapentin could be due to effect of the drug in reduction of allodynia and hyperalgesia effect and central sensitization after the elicitation of postsurgical pain. The other effects of Gabapentin particularly decreasing the nausea and vomiting postoperatively, anxiolysis and some degree of sedation could be other possible indirect mechanism postulated which would have also altered the perception of pain of an individual and thereby reducing the demand of analgesia.

VAS at rest was found to be decreased with statistical significance at 2 and 24 hours after surgery (Table 3. and Figure 1). In study at similar dose involving lower extremity orthopedic surgery showed similar results where VAS score was reduced significantly in 2, 4, and 24 hours. ${ }^{13}$ Similarly pain score also reduced at 4 and 24 hours after minilaparascopic cholecystectomy with $600 \mathrm{mg}$ Gabapentin given two hour prior to surgery. ${ }^{7}$ At $600 \mathrm{mg}$ dose of Gabapentin, many studies showed reduction in pain scores postoperatively but at various duration. ${ }^{8,9,15}$ At $900 \mathrm{mg}$ there was also significant reduction in pain scores at 2, 4, 6 and 24 hours postoperatively with surgery involving abdominal hysterectomy. ${ }^{16}$ But at $300 \mathrm{mg}$ doses, VAS score at rest during 2 hours was significantly reduced, with no reduction at 24 hour. ${ }^{17}$

Sedation score at $600 \mathrm{mg}$ Gabapentin was minimal and comparable with control in our study. Other studies involving $600 \mathrm{mg}$ dose, incidence of sedation was comparable..$^{8,9,18}$ A study done under general anesthesia at $600 \mathrm{mg}$ also showed higher incidences of sedation. ${ }^{7}$ At $300 \mathrm{mg}$ doses in lower extremity surgery under subarachnoid block, oral Gabapentin didn't show any side effects. ${ }^{14,17}$ At higher doses of $1200 \mathrm{mg}$ compared to placebo in study where patients had undergone lower extremity surgery under subarachnoid block suggested a higher sedation score. ${ }^{19}$

There is a possibility of different pain perception among different types of lower orthopedic surgeries. Likewise, there was also heterogeneity of level of tissue trauma as different surgeries were performed by different 
surgeons. VAS assessment of pain itself has its own limitation. There was variability in interpretation of perception of pain by different individual with different races and different literacy status. The tolerance level of individual was also not taken in consideration which would also give the false scoring.

\section{CONCLUSIONS}

Preemptive oral Gabapentin 600 mg used 2 hour prior to lower extremity surgeries undergoing subarachnoid block decreases total opioid consumption in first 24 hours after surgery. It also reduces VAS score at 2 and 24 hours at rest postoperatively with minimum sedation.

\section{REFERENCES}

1. Dahl JB, Moiniche S. Pre-emptive analgesia. Br Med Bull. 2004;71:13-27.

2. Kong VK, Irwin MG. Gabapentin: a multimodal perioperative drug? Br J Anaesth. 2007;99(6):775-86.

3. Rose M, Kam P. Gabapentin: pharmacology and its use in pain management. Anaesthesia. 2002;57(5):451-62.

4. Pharmacotherapy of the Epilepsies. Brunton L, Parker K, Blumenthal D, I. B, editors. USA: McGraw Hill Companies; 2008. 331-2 p.

5. Dawson R, von Fintel N, Nairn S. Sedation assessment using the Ramsay scale. Emergency nurse: the journal of the RCN Accident and Emergency Nursing Association. 2010;18(3):18-20.

6. Hurley RW, Cohen SP, Williams KA, Rowlingson AJ, Wu CL. The analgesic effects of perioperative gabapentin on postoperative pain: a meta-analysis. Reg Anesth Pain Med. 2006;31(3):237-47.

7. Srivastava U, Kumar A, Saxena S, Mishra AR, Saraswat N, Mishra S. Effect of preoperative gabapentin on postoperative pain and tramadol consumption after minilap open cholecystectomy: a randomized double-blind, placebo-controlled trial. Eur J Anaesthesiol. 2010;27(4):331-5.

8. Grover VK, Mathew PJ, Yaddanapudi S, Sehgal S. A single dose of preoperative gabapentin for pain reduction and requirement of morphine after total mastectomy and axillary dissection: randomized placebo-controlled double-blind trial. J Postgrad Med. 2009;55(4):257-60.

9. Bharti N, Bala I, Narayan V, Singh G. Effect of gabapentin pretreatment on propofol consumption, hemodynamic variables, and postoperative pain relief in breast cancer surgery. Acta Anaesthesiologica Taiwanica. 2013;51(1):10-3.

10. Pandey CK, Priye S, Singh S, Singh U, Singh RB, Singh PK. Preemptive use of gabapentin significantly decreases postoperative pain and rescue analgesic requirements in laparoscopic cholecystectomy. Canadian Journal of Anesthesia. 2004;51(4):358-63.
11. Tiippana EM, Hamunen K, Kontinen VK, Kalso E. Do surgical patients benefit from perioperative gabapentin/ pregabalin? A systematic review of efficacy and safety. Anesthesia \& Analgesia. 2007;104(6):1545-56.

12. Clivatti J, Sakata RK, Issy AM. Review of the use of gabapentin in the control of postoperative pain. Brazilian Journal of Anesthesiology. 2009;59(1):87-98.

13. Montazeri K, Kashefi P, Honarmand A. Pre-emptive gabapentin significantly reduces Postoperative pain and morphine demand following lower extremity orthopaedic surgery. Singapore Med J. 2007;48(8):748-51.

14. Bang SR, Yu SK, Kim TH. Can gabapentin help reduce postoperative pain in arthroscopic rotator cuff repair? A prospective, randomized, double-blind study. Arthroscopy: The Journal of Arthroscopic \& Related Surgery. 2010;26(9):S106-S11.

15. Moore A, Costello J, Wieczorek P, Shah V, Taddio A, Carvalho JC. Gabapentin improves postcesarean delivery pain management: a randomized, placebo-controlled trial. Anesth Analg. 2011;112(1):167-73

16. Ghai A, Gupta M, Hooda S, Singla D, Wadhera R. A randomized controlled trial to compare pregabalin with gabapentin for postoperative pain in abdominal hysterectomy. Saudi journal of anaesthesia. 2011;5(3):252-7.

17. Panah Khahi M, Yaghooti AA, Marashi SH, Nadjafi A. Effect of pre-emptive gabapentin on postoperative pain following lower extremity orthopaedic surgery under spinal anaesthesia. Singapore Med J. 2011;52(12):879-82.

18. Montazeri K, Kashefi P, Honarmand A. Pre-emptive gabapentin significantly reduces postoperative pain and morphine demand following lower extremity orthopaedic surgery. Singapore medical journal. 2007;48(8):748-51.

19. Raghove P, Jaiswal R, Singh K. Evaluating the effect of preoperative oral gabapentin on postoperative pain in patients receiving spinal anaesthesia for lower limb surgery. Southern African Journal of Anaesthesia and Analgesia. 2010;16(6):9-12. 